\title{
The effect of magnesium added to bupivacaine for arthroscopy: a meta- analysis of randomized controlled trials
}

\author{
Weineng Xiang ${ }^{*}$, Lin Jiang ${ }^{*}$, Langtao Shi, Chengming Jiang, Yun Zhou and Chunhua Yang
}

\begin{abstract}
Introduction: The analgesic efficacy of magnesium sulphate added to bupivacaine for arthroscopy remains controversial. We conduct a systematic review and meta-analysis to explore the efficacy of magnesium sulphate in combination with bupivacaine for arthroscopy.

Methods: We searched PubMed, EMbase, Web of science, EBSCO, and Cochrane library databases through July 2020 for randomized controlled trials (RCTs) assessing the effect of magnesium sulphate plus bupivacaine versus bupivacaine for arthroscopy. This meta-analysis is performed using the random-effect model.

Results: Six RCTs were included in the meta-analysis. Overall, compared with bupivacaine for arthroscopy, combination analgesia using magnesium plus bupivacaine was associated with significantly prolonged duration of analgesia $(\mathrm{SMD}=0.93 ; 95 \% \mathrm{Cl}=0.27$ to $1.60 ; \mathrm{P}=0.006)$ and first time to analgesic requirement $(\mathrm{SMD}=196.57 ; 95 \% \mathrm{Cl}=$ 13.90 to $379.24 ; \mathrm{P}=0.03)$, reduced pain scores $(\mathrm{SMD}=-1.71 ; 95 \% \mathrm{Cl}=-2.96$ to $-0.46 ; \mathrm{P}=0.007)$ and analgesic consumption ( $\mathrm{SMD}=-1.04 ; 95 \% \mathrm{Cl}=-1.49$ to $-0.60 ; \mathrm{P}<0.00001)$, but showed no remarkable influence on nausea or vomiting ( $\mathrm{OR}=1.54 ; 95 \% \mathrm{Cl}=0.60$ to $3.97 ; \mathrm{P}=0.37)$.
\end{abstract}

Conclusions: Magnesium sulphate added to bupivacaine may significantly improve the analgesic efficacy for arthroscopy.

Keywords: magnesium sulphate, bupivacaine, arthroscopy, randomized controlled trials, meta-analysis

\section{Introduction}

Arthroscopic surgeries are commonly used for various diagnostic and therapeutic purposes [1-4]. However, they may result in serious postoperative pain in some patients. Adequate pain relief is crucial for early mobilization, rehabilitation and discharge of patients [58]. Several strategies have been developed to achieve optimal analgesia, and include systemic narcotics, nonsteroidal anti-inflammatory drugs, neuraxial analgesia (spinal/epidural), peripheral nerve blocks, intravenous patient-controlled analgesia, periarticular (e.g.

\footnotetext{
*Correspondence: xiangweineng@163.com; 43452453@qq.com Department of Spin Surgery, The First Hospital of Changsha, NO.311 Yingpan Road, Kaifu District, Changsha City, Hunan, China
}

subcutaneous, intra-articular) infiltration with local anesthetics $[9,10]$.

Many local anesthetics were used for arthroscopy, such as lignocaine, bupivacaine, ropivacaine, morphine, fentanyl, sufentanil, pethidine, clonidine, dexmedetomidine, magnesium, ketorolac, tramadol, and neostigmine et al [11-13]. However, there are still some limitations such as short duration of action, restricted availability in the wards, and need for stringent monitoring for any side effects. Optimal modality can provide excellent analgesia with minimal side effects, lower opioid use and enhance rehabilitation. Bupivacaine was commonly used for the analgesia of arthroscopy $[12,14]$. Magnesium sulfate acts as an NMDA (N-Methyl-D-Aspartate) receptor

C C The Author(s). 2021 Open Access This article is licensed under a Creative Commons Attribution 4.0 International License, which permits use, sharing, adaptation, distribution and reproduction in any medium or format, as long as you give appropriate credit to the original author(s) and the source, provide a link to the Creative Commons licence, and indicate if changes were made. The images or other third party material in this article are included in the article's Creative Commons. licence, unless indicated otherwise in a credit line to the material. If material is not included in the article's Creative Commons licence and your intended use is not permitted by statutory regulation or exceeds the permitted use, you will need to obtain permission directly from the copyright holder. To view a copy of this licence, visit http://creativecommons.org/licenses/by/4.0/ The Creative Commons Public Domain Dedication waiver (http://creativecommons.org/publicdomain/zero/1.0/) applies to the data made available in this article, unless otherwise stated in a credit line to the data. 
antagonist, and was found to improve the pain management after arthroscopic meniscectomy when added to levobupivacaine [15].

Several studies reported the magnesium sulfate plus bupivacaine versus bupivacaine for arthroscopic surgery, but their efficacy has not been well established [15-18]. With accumulating evidence, we therefore perform a systematic review and meta-analysis of RCTs to compare the analgesic efficacy of magnesium sulfate plus bupivacaine versus bupivacaine for arthroscopy.

\section{Materials and methods}

Ethical approval and patient consent were not required because this was a systematic review and meta-analysis of previously published studies. The systematic review and meta-analysis were conducted and reported in adherence to PRISMA (Preferred Reporting Items for Systematic Reviews and Meta-Analyses) [19].

\section{Search strategy and study selection}

Two investigators have independently searched the following databases (inception to July 2020): PubMed, EMbase, Web of science, EBSCO, and Cochrane library databases. The electronic search strategy was conducted using the following keywords: magnesium, and bupivacaine, and arthroscopy or arthroscopic surgery. We also check the reference lists of the screened full-text studies to identify other potentially eligible trials.

The inclusive selection criteria were as follows: (i) patients underwent knee arthroscopy; (ii) intervention treatments were magnesium sulphate plus bupivacaine versus bupivacaine; (iii) study design was RCT.

\section{Data extraction and outcome measures}

We have extracted the following information: author, number of patients, age, female, weight, duration of surgery and detail methods in each group etc. Data were extracted independently by two investigators, and discrepancies were resolved by consensus. We also contacted the corresponding author to obtain the data when necessary.

The primary outcomes were duration of analgesia and pain scores. Secondary outcomes included first time to analgesic requirement, analgesic consumption, nausea and vomiting.

\section{Quality assessment in individual studies}

Methodological quality of the included studies was independently evaluated using the modified Jadad scale [20]. There was 3 items for Jadad scale: randomization (0-2 points), blinding (0-2 points), dropouts and withdrawals (0-1 points). The score of Jadad Scale varied from 0 to 5 points. An article with Jadad score $\leq 2$ was considered to be of low quality. If the Jadad score $\geq 3$, the study was thought to be of high quality [21].

\section{Statistical analysis}

We estimate the standard mean difference (SMD) with 95\% confidence interval (CI) for continuous outcomes (duration of analgesia, pain scores, first time to analgesic requirement, and analgesic consumption) and odd ratio (OR) with $95 \% \mathrm{CI}$ for dichotomous outcomes (nausea and vomiting). The random-effects model was used regardless of heterogeneity. Heterogeneity was reported using the $\mathrm{I}^{2}$ statistic, and $\mathrm{I}^{2}>50 \%$ indicated significant heterogeneity [22]. Whenever significant heterogeneity was present, we searched for potential sources of heterogeneity via omitting one study in turn for the metaanalysis or performing subgroup analysis. All statistical analyses were performed using Review Manager Version 5.3 (The Cochrane Collaboration, Software Update, Oxford, UK).

\section{Results}

Literature search, study characteristics and quality assessment

A detailed flowchart of the search and selection results was shown in Fig. 1. 239 potentially relevant articles were identified initially. 91 duplicates and 138 papers after checking the titles/abstracts were excluded. Six RCTs were ultimately included in the meta-analysis [15-18, 23, 24].

The baseline characteristics of the six eligible RCTs in the meta-analysis were summarized in Table 1 . The six studies were published between 2008 and 2018, and sample sizes ranged from 36 to 60 with a total of 312 . Among the six included RCTs, there were knee arthroscopy $[15,16,18,23,24]$ and shoulder arthroscopy [17]. The doses of magnesium sulphate ranged from $50 \mathrm{mg}$ to $1.5 \mathrm{~g}$. Two studies reported duration of analgesia [16, 17], two studies reported pain scores [15, 17], two studies reported first time to analgesic requirement $[18,23]$, four studies reported analgesic consumption $[15,18,23$, $24]$, two studies reported nausea and vomiting [17, 23]. Jada scores ranged from 3 to 5 , and thus these six included generally had high quality.

Primary outcomes: duration of analgesia and pain scores These outcome data were analyzed with the randomeffects model, and compared to bupivacaine for arthroscopy, combination analgesia using magnesium plus bupivacaine was associated with significantly prolonged duration of analgesia (SMD $=0.93 ; 95 \% \mathrm{CI}=0.27$ to 1.60 ; $\mathrm{P}=0.006)$ with significant heterogeneity among the studies $\left(\mathrm{I}^{2}=55 \%\right.$, heterogeneity $\left.\mathrm{P}=0.13\right)$ (Fig. 2$)$ and reduced pain scores $(\mathrm{SMD}=-1.71 ; 95 \% \mathrm{CI}=-2.96$ to $-0.46 ; \mathrm{P}=$ 


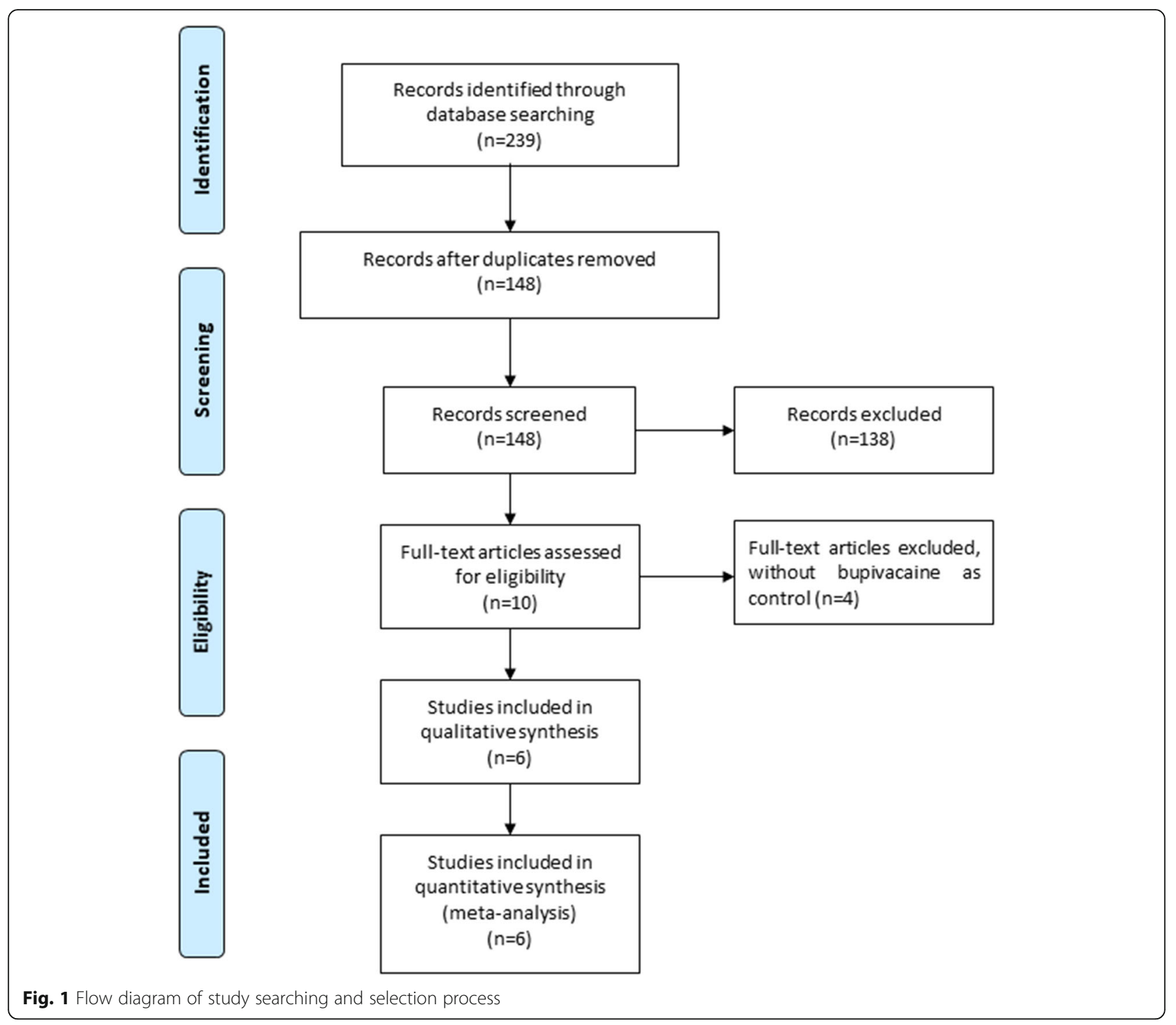

$0.007)$ with significant heterogeneity among the studies $\left(\mathrm{I}^{2}=88 \%\right.$, heterogeneity $\mathrm{P}=0.004$ ) (Fig. 3 ).

\section{Sensitivity analysis}

Significant heterogeneity was observed for the primary outcomes. There were only two studies included, and thus we did not perform the sensitivity analysis by omitting one study in turn or the subgroup analysis.

\section{Secondary outcomes}

In comparison with bupivacaine for arthroscopy, combination analgesia could substantially increase the first time to analgesic requirement $(\mathrm{SMD}=196.57 ; 95 \% \mathrm{CI}=$ 13.90 to 379.24 ; $\mathrm{P}=0.03$; Fig. 4 ), and reduce the analgesic consumption (SMD $=-1.04 ; 95 \% \mathrm{CI}=-1.49$ to $-0.60 ; \mathrm{P}<0.00001$; Fig. 5), but revealed no obvious effect on nausea or vomiting $(\mathrm{OR}=1.54 ; 95 \% \mathrm{CI}=0.60$ to 3.97; $\mathrm{P}=0.37$; Fig. 6).

\section{Discussion}

Surgical excision and resection in arthroscopy produce postoperative pain because of irritation of free nerve ending of synovial tissue, anterior fat pad, and joint capsule [25-27]. Preoperative evaluation, appropriate intraoperative management and early postoperative mobilization are crucial for the anesthesia for ambulatory surgery needs good $[28,29]$. Multimodal analgesia has become a promising approach for postoperative pain relief. For instance, intraarticular analgesic agents are used as a simple and cost-effective approach via acting on peripheral receptors and providing analgesia locally with minimal systemic side effects. The local tissue 


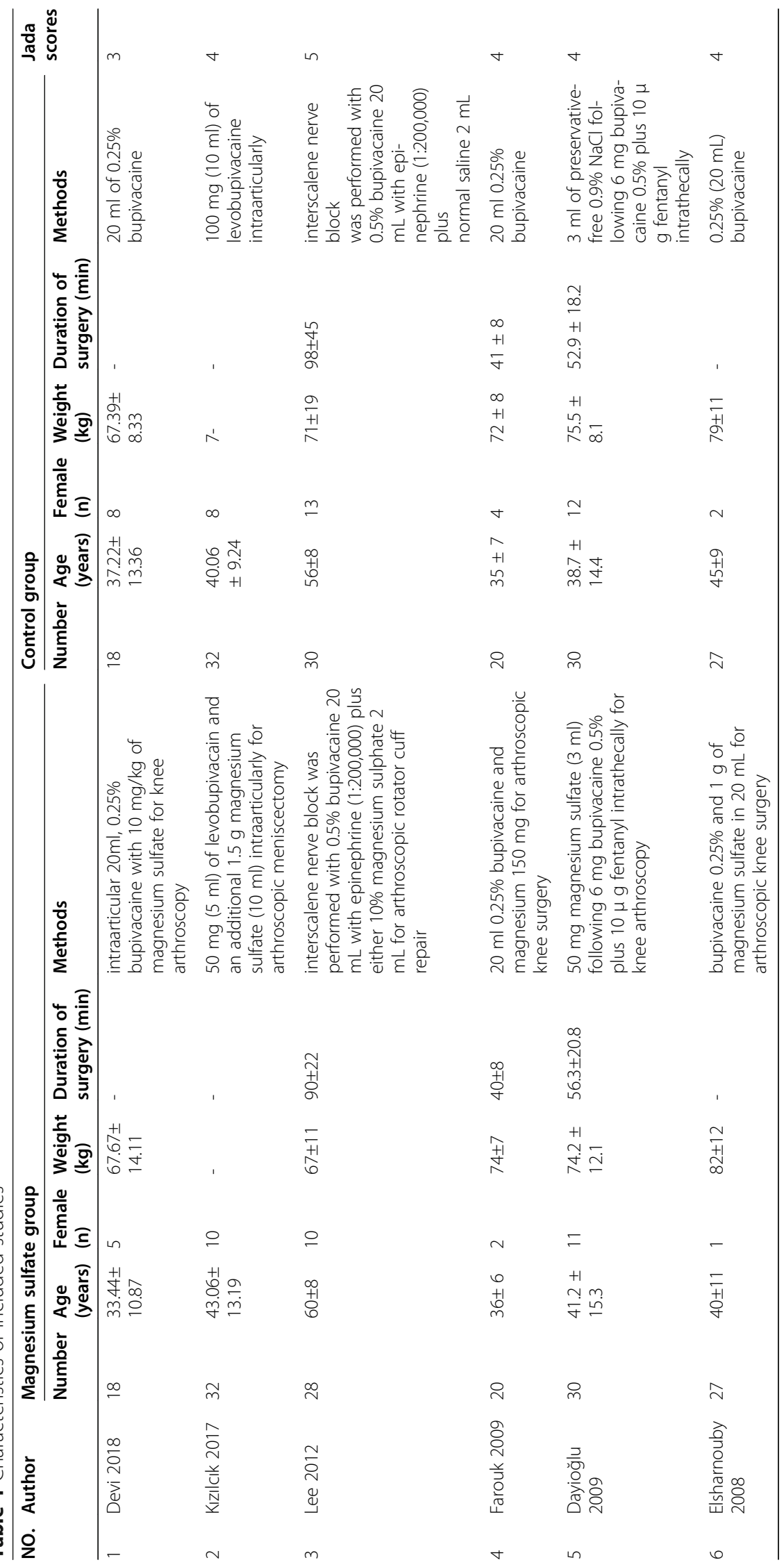




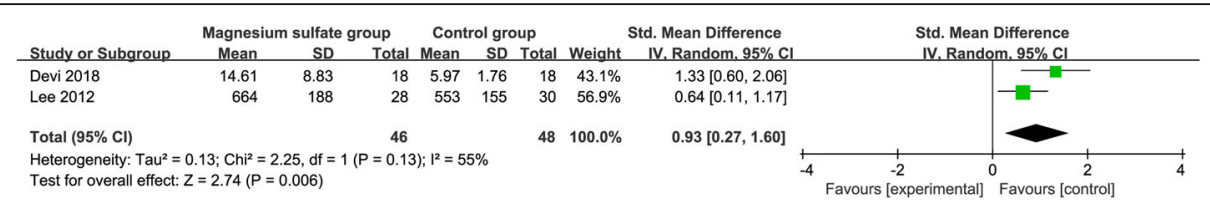

Fig. 2 Forest plot for the meta-analysis of duration of analgesia

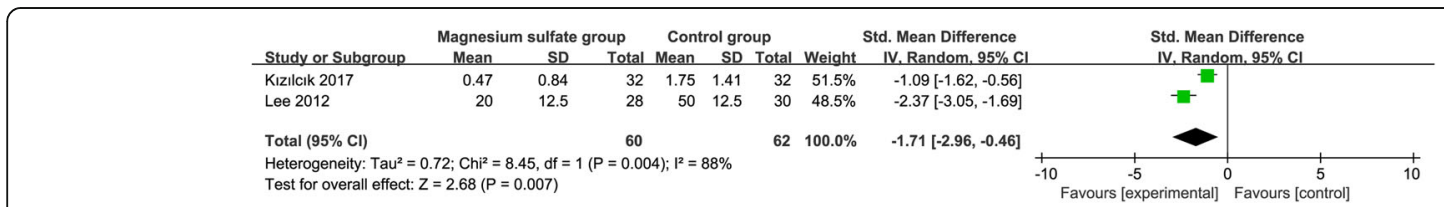

Fig. 3 Forest plot for the meta-analysis of pain scores

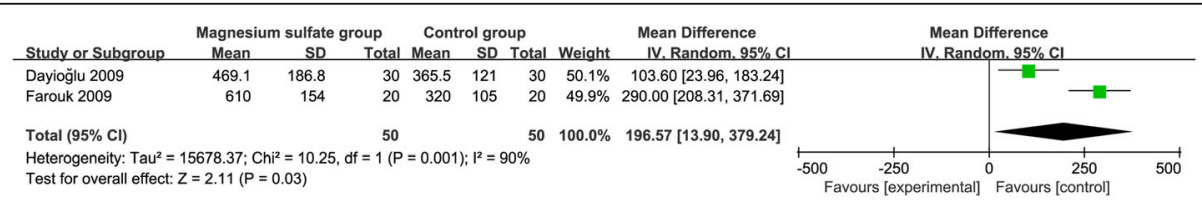

Fig. 4 Forest plot for the meta-analysis of first time to analgesic requirement

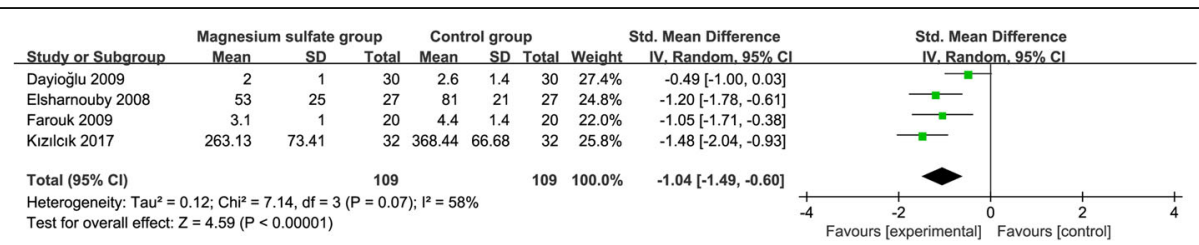

Fig. 5 Forest plot for the meta-analysis of analgesic consumption

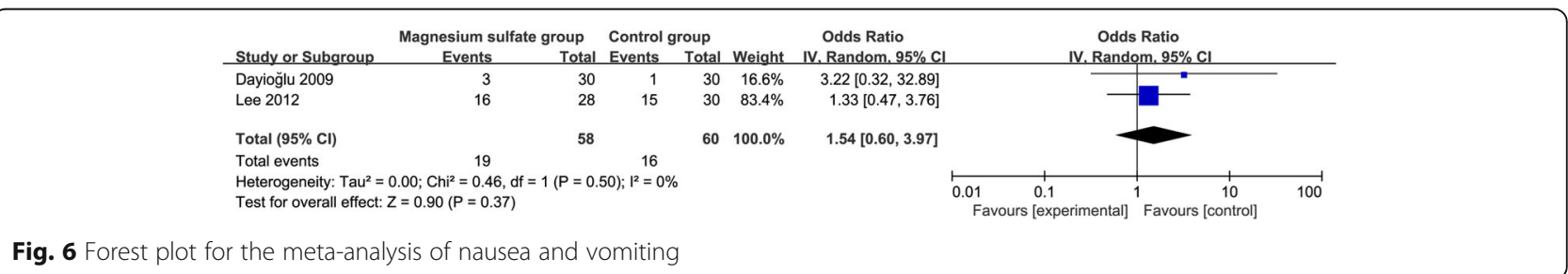

Fig. 6 Forest plot for the meta-analysis of nausea and vomiting 
binding to receptors can be increased in order to enhance the analgesic effect [30].

Local anesthetics such as bupivacaine may exert chondrotoxicity by reducing chondrocyte viability in arthroscopy surgeries [31]. The incidence of chondrolysis following local administration of bupivacaine seems to be low or possibly underreported [32]. Bupivacaine is combined with adjuvants (e.g. opioids, $\mathrm{Mg}$, tramadol, clonidine and dexmedetomidine) to provide prolonged postoperative analgesia and reduce the dose of analgesics. N-methyl D-aspartate (NMDA) receptors widely exist centrally and peripherally in the joints, muscles, and skin. They account for central nociceptive transmission, modulation, and sensitization of acute pain states [33]. Mg can serve as an efficacious adjunct, therefore enhancing postoperative analgesia when used by intravenous, intraarticular and epidural routes [14, 33, 34]. Its antinociceptive effect is produced by blocking NMDA receptors and decreasing the entry of extracellular calcium into cells, thereby exhibiting chondrocyte protective effect [24].

The main findings of this meta-analysis suggested that combination analgesia using magnesium plus bupivacaine could significantly prolong the duration of analgesia and first time to analgesic requirement, reduce pain scores and analgesic consumption than only bupivacaine for arthroscopic surgeries, but there was no increase in nausea and vomiting after magnesium plus bupivacaine intervention. Significant heterogeneity remained when performing the sensitivity analysis, and several factors may account for it. Firstly, different types and operation procedures can produce different levels of pain intensity, which may affect the pooling results. Secondly, the doses of magnesium sulphate ranged from 50 $\mathrm{mg}$ to $1.5 \mathrm{~g}$, and produce different promotion to pain relief. Thirdly, the routes of local analgesics included intraarticular and spinal anesthesia.

This meta-analysis has several potential limitations. Firstly, our analysis is based on six RCTs, and all of them have a relatively small sample size $(n<100)$. These may lead to overestimation of the treatment effect in smaller trials. More RCTs with large sample size should be conducted to explore this issue. Next, different doses and routes of drugs may contribute to the significant heterogeneity. Finally, different types and operation procedures can produce different levels of pain intensity, which may produce some effect on the results.

\section{Conclusions}

Combination analgesia using magnesium plus bupivacaine may provide better analgesic efficacy for arthroscopy than as compared to only bupivacaine.

\section{Abbreviations}

RCTs: Randomized controlled trials; MDs: Mean differences; Cls: Confidence intervals; RRs: risk ratios

\section{Acknowledgements}

None

\section{Availability of supporting data}

Not applicable.

\begin{abstract}
Authors' contributions
Weineng Xiang and Lin Jiang conducted the design, Langtao Shi and Chengming Jiang conducted the study planning, data analysis and data interpretation, Yun Zhou and Chunhua Yang wrote and revised the article. All authors read and approved the final manuscript.
\end{abstract}

Funding

Not applicable.

\section{Declarations}

Ethical Approval and Consent to participate

Not applicable.

Consent for publication

Not applicable.

Competing interests

The authors declare no conflict of interest.

Received: 18 August 2020 Accepted: 30 November 2020

Published online: 10 October 2021

\section{References}

1. Sihvonen R, Paavola M, Malmivaara A, Itälä A, Joukainen A, Nurmi H, et al. Arthroscopic partial meniscectomy versus sham surgery for a degenerative meniscal tear. N Engl J Med. 2013;369(26):2515-24.

2. Kise NJ, Risberg MA, Stensrud S, Ranstam J, Engebretsen L, Roos EM. Exercise therapy versus arthroscopic partial meniscectomy for degenerative meniscal tear in middle aged patients: randomised controlled trial with two year follow-up. BMJ (Clinical research ed). 2016;354:i3740.

3. Beard DJ, Rees JL, Cook JA, Rombach I, Cooper C, Merritt N, et al. Arthroscopic subacromial decompression for subacromial shoulder pain (CSAW): a multicentre, pragmatic, parallel group, placebo-controlled, threegroup, randomised surgical trial. Lancet (London, England). 2018;391(10118): 329-38.

4. Sihvonen R, Paavola M, Malmivaara A, Itälä A, Joukainen A, Nurmi H, et al. Arthroscopic partial meniscectomy versus placebo surgery for a degenerative meniscus tear: a 2-year follow-up of the randomised controlled trial. Ann Rheum Dis. 2018:77(2):188-95.

5. Mahure SA, Rokito AS, Kwon YW. Transcutaneous electrical nerve stimulation for postoperative pain relief after arthroscopic rotator cuff repair: a prospective double-blinded randomized trial. J Shoulder Elb Surg. 2017; 26(9):1508-13.

6. Pham TT, Bayle Iniguez X, Mansat P, Maubisson L, Bonnevialle N. Postoperative pain after arthroscopic versus open rotator cuff repair. A prospective study. Orthopaedics \& traumatology, surgery \& research: OTSR. 2016;102(1):13-7.

7. Daniels SD, Garvey KD, Collins JE, Matzkin EG. Patient Satisfaction With Nonopioid Pain Management Following Arthroscopic Partial Meniscectomy and/or Chondroplasty. Arthroscopy: the journal of arthroscopic \& related surgery: official publication of the Arthroscopy Association of North America and the International Arthroscopy Association. 2019;35(6):1641-7.

8. Cheatham SW, Enseki KR, Kolber MJ. Postoperative Rehabilitation After Hip Arthroscopy: A Search for the Evidence. J Sport Rehabil. 2015;24(4):413-8.

9. Terkawi AS, Mavridis D, Sessler DI, Nunemaker MS, Doais KS, Terkawi RS, et al. Pain Management Modalities after Total Knee Arthroplasty: A Network Meta-analysis of 170 Randomized Controlled Trials. Anesthesiology. 2017; 126(5):923-37.

10. Manuar MB, Majumdar S, Das A, Hajra BK, Dutta S, Mukherjee D, et al. Pain relief after Arthroscopic Knee Surgery: A comparison of intra-articular ropivacaine, fentanyl, and dexmedetomidine: A prospective, double-blinded, randomized controlled study. Saudi J Anaesth. 2014;8(2):233-7. 
11. Zou Z, An MM, Xie Q, Chen XY, Zhang H, Liu GJ, et al. Single dose intraarticular morphine for pain control after knee arthroscopy. The Cochrane database of systematic reviews 2016. 2016:5:Cd008918.

12. Li C, Qu J. Efficacy of dexmedetomidine for pain management in knee arthroscopy: A systematic review and meta-analysis. Medicine. 2017;96(43): e7938.

13. Sun QB, Liu SD, Meng QJ, Qu HZ, Zhang Z. Single administration of intraarticular bupivacaine in arthroscopic knee surgery: a systematic review and meta-analysis. BMC Musculoskelet Disord. 2015;16:21.

14. Zeng C, Li YS, Wei J, Xie DX, Xie X, Li LJ, et al. Analgesic effect and safety of single-dose intra-articular magnesium after arthroscopic surgery: a systematic review and meta-analysis. Sci Rep. 2016;6:38024.

15. Kızılcık N, Özler T, Menda F, Uluçay Ç, Köner Ö, Altıntaş F. The effects of intra-articular levobupivacain versus levobupivacain plus magnesium sulfate on postoperative analgesia in patients undergoing arthroscopic meniscectomy: A prospective randomized controlled study. Acta Orthop Traumatol Turc. 2017:51(2):104-9.

16. Devi MM, Gupta S, Amaravathi R, Udupa S, Hegde A, Ghosh S. Comparison of Efficacy of Intra-Articular Plain Bupivacaine and Bupivacaine with Adjuvants (Dexmedetomidine and Magnesium Sulfate) for Postoperative Analgesia in Arthroscopic Knee Surgeries: A Prospective. Randomized Controlled Trial, Anesthesia, essays and researches. 2018;12(4):848-54.

17. Lee AR, Yi HW, Chung IS, Ko JS, Ahn HJ, Gwak MS, et al. Magnesium added to bupivacaine prolongs the duration of analgesia after interscalene nerve block. Canadian journal of anaesthesia $=$ Journal canadien d'anesthesie. 2012;59(1):21-7.

18. Farouk S, Aly A. A comparison of intra-articular magnesium and/or morphine with bupivacaine for postoperative analgesia after arthroscopic knee surgery. J Anesth. 2009;23(4):508-12.

19. Moher D, Liberati A, Tetzlaff J, Altman DG, P. Group. Preferred reporting items for systematic reviews and meta-analyses: the PRISMA statement. J Clin Epidemiol. 2009;62(10):1006-12.

20. Jadad AR, Moore RA, Carroll D, Jenkinson C, Reynolds DJM, Gavaghan DJ, et al. Assessing the quality of reports of randomized clinical trials: Is blinding necessary? Control Clin Trials. 1996;17(1):1-12.

21. Kjaergard LL, Villumsen J, Gluud C. Reported Methodologic Quality and Discrepancies between Large and Small Randomized Trials in MetaAnalyses. Ann Intern Med. 2001;135(11):982-9.

22. Higgins JP, Thompson SG. Quantifying heterogeneity in a meta-analysis. Stat Med. 2002;21(11):1539-58.

23. Dayioğlu H, Baykara ZN, Salbes A, Solak M, Toker K. Effects of adding magnesium to bupivacaine and fentanyl for spinal anesthesia in knee arthroscopy. J Anesth. 2009;23(1):19-25.

24. Elsharnouby NM, Eid HE, Abou Elezz NF, Moharram AN. Intraarticular injection of magnesium sulphate and/or bupivacaine for postoperative analgesia after arthroscopic knee surgery. Anesth Analg. 2008;106(5):154852 table of contents.

25. Al-Metwalli RR, Mowafi HA, Ismail SA, Siddiqui AK, Al-Ghamdi AM, Shafi MA, et al. Effect of intra-articular dexmedetomidine on postoperative analgesia after arthroscopic knee surgery. Br J Anaesth. 2008;101(3):395-9.

26. Onda A, Ogoshi A, Itoh M, Nakagawa T, Kimura M. Comparison of the effects of treatment with celecoxib, loxoprofen, and acetaminophen on postoperative acute pain after arthroscopic knee surgery: A randomized, parallel-group trial. Journal of orthopaedic science : official journal of the Japanese Orthopaedic Association. 2016;21(2):172-7.

27. Cuff DJ, O'Brien KC, Pupello DR, Santoni BG. Evaluation of Factors Affecting Acute Postoperative Pain Levels After Arthroscopic Rotator Cuff Repair. Arthroscopy : the journal of arthroscopic \& related surgery : official publication of the Arthroscopy Association of North America and the International Arthroscopy Association. 2016;32(7):1231-6.

28. Kulkarni S, Harsoor S, Chandrasekar M, Bhaskar SB, Bapat J, Ramdas EK, et al. Consensus statement on anaesthesia for day care surgeries. Indian journal of anaesthesia. 2017;61(2):110.

29. Thorlund JB, Juhl CB, Roos EM, Lohmander L. Arthroscopic surgery for degenerative knee: systematic review and meta-analysis of benefits and harms. bmj. 2015;350:h2747.

30. Whitford A, Healy M, Joshi GP, McCarroll SM, O'Brien TM. The effect of tourniquet release time on the analgesic efficacy of intraarticular morphine after arthroscopic knee surgery. Anesth Analg. 1997:84(4):791-3.
31. Breu A, Rosenmeier K, Kujat R, Angele P, Zink W. The cytotoxicity of bupivacaine, ropivacaine, and mepivacaine on human chondrocytes and cartilage. Anesth Analg. 2013;117(2):514-22.

32. Scheffel PT, Clinton J, Lynch JR, Warme WJ, Bertelsen AL, Matsen FA 3rd. Glenohumeral chondrolysis: a systematic review of 100 cases from the English language literature. J Shoulder Elb Surg. 2010;19(6):944-9.

33. Saritas TB, Borazan H, Okesli S, Yel M, Otelcioglu Ş. Is intra-articular magnesium effective for postoperative analgesia in arthroscopic shoulder surgery? Pain Res Manag. 2015;20(1):35-8.

34. Xu X, Wen H, Hu Y, Liu Z, Pan X. Efficacy of intra-articular magnesium for postoperative analgesia in total hip arthroplasty. Biomedical reports. 2017; $6(2): 232-6$.

\section{Publisher's Note}

Springer Nature remains neutral with regard to jurisdictional claims in published maps and institutional affiliations.
Ready to submit your research? Choose BMC and benefit from:

- fast, convenient online submission

- thorough peer review by experienced researchers in your field

- rapid publication on acceptance

- support for research data, including large and complex data types

- gold Open Access which fosters wider collaboration and increased citations

- maximum visibility for your research: over $100 \mathrm{M}$ website views per year

At BMC, research is always in progress.

Learn more biomedcentral.com/submissions 